
\title{
25 Research Soure \\ Prognostic Nomogram for Penile Cancer, an Analysis Based on SEER Database
}

\author{
Yong-Bo Chen \\ Peoples Hospital of Deyang City \\ Liang Gao \\ the second affiliated hospital of chongqing medical university \\ Liang-You Tang \\ Peoples Hospital of Deyang City \\ Jiang Guo \\ the second affiliated hospital of chongqing medical university \\ Yu-Chang Tian \\ Peoples Hospital of Deyang City \\ Ping-Hong You ( $\sim$ yamyou@126.com ) \\ Peoples Hospital of Deyang City https://orcid.org/0000-0002-0521-5399
}

\section{Research article}

Keywords: penile cancer, prognostic nomogram, SEER database

Posted Date: August 26th, 2020

DOI: https://doi.org/10.21203/rs.3.rs-50766/v1

License: (c) (i) This work is licensed under a Creative Commons Attribution 4.0 International License. Read Full License 


\section{Abstract}

Background: We aimed to establish a prognostic nomogram for Penile Cancer (PC) patients based on the Surveillance, Epidemiology, and End Results Program (SEER) database.

Methods: Data of 1694 patients between 2010 and 2015 were downloaded and extracted from the SEER database. Then, they were randomly divided into the development group (70\%) and the verification group (30\%). Following, the univariate and multivariate Cox proportional hazards regression was respectively used to explore the possible risk factors of PC. Factors which significantly related to the overall survival (OS) were used to establish the nomogram. Further, the concordance index (C-index), receiver operating characteristic curve (ROC) and calibration curve were used to assess the nomogram, respectively. An internal validation was carried out to test the accuracy and effectiveness of nomogram. Finally, the Kaplan-Meier calculation was used to predict the further survival status of these patients.

Results: Multivariate Cox proportional hazards regression demonstrated that the independent prognostic risk factors associated with PC were age, stage T, N and M, and grade, with a moderate c-index of 0.732 [95\% confidence interval ( $\mathrm{Cl}), 0.706-0.757$ ] in development group and 0.743 (95\% $\mathrm{Cl}, 0.703-0.782)$ in verification group. Meanwhile, the areas under the ROC (AUC) of 3-year and 5-year survival were 0.739 and 0.727 , respectively. The survival calibration curves of 3-year and 5-year brought out a high consistency.

Conclusion: Our study obtained a satisfactory nomogram to reveal the survival of PC patients, which could be helpful for clinicians to assess the situation of PC patients and to implement the further treatment.

\section{Introduction}

Although the incidence increased slightly in some areas in recent years, penile cancer (PC) was still a relatively rare malignancy in developed countries [1-3]. It had been showed that multiple etiologies might have contributed the occurrence of this disease, such as human papillomavirus (HPV) infection, phimosis, lichen sclerosus, smoking, condylomata acuminate, sexual problems, and chronic inflammation, etc. [4-10].

Because of its high mortality, a clinical model to predicting the prognosis of PC patients would be necessary [11]. Although the TNM stage and pathological classification systems, from the 8th American Joint Committee on Cancer (AJCC) and the Union for International Cancer Control (UICC), were widely used to predict the survival of PC patients [12,13], a lot of limitations existed. However, the SEER database had collected the detailed information of PC patients, which allowed us to build a reliable prognostic nomogram.

\section{Materials And Methods}

After registered an account and signed a Data Agreement on SEER database website, we were authorized to download all data of PC patients using the SEER $*$ Stat version 8.3.5 software. All available data on the patients' age, race, stage T/N/M (AJCC 7th standard 2010+), grade, survival time, and live status were collected. Cases with unknown, undefined and missing data were excluded. "Caret" package of R version 3.6.0 software was utilized to randomize the patients into development group (70\%) and verification group (30\%). In addition, in our study, patients whose race was not black or white were described as "others". 
R version 3.6.0 software with "foreign", "survival", "survminer" and "rms" packages was used to all statistical analyses, and $\mathrm{P}$ value $<0.05$ was regarded to be statistically significant. Every parameter was firstly calculated by the univariate and multivariate Cox proportional hazards regression model and resulted as hazard ratio (HR) and 95\% confidence interval (Cl). Then, possible risk factors were identified. Finally, the prognostic nomogram using data from the development group was conducted to predict patients' further survival.

C-index, AUC and calibration curves of 3-year and 5-year survival were calculated to verify the accuracy of the nomogram. Higher C-index and more AUC meant higher quality. As many as possible of bootstraps with 3000 resamples were set up to make sure the precision of 3- and 5-year calibrations in the comparison between the predicted and observed survival. Further, the Kaplan-Meier analysis was also used to demonstrate patients' possible survival.

\section{Results}

According to the screening criteria, 7315 males between 2010 and 2015 were involved in our study, from which 5621 patients were excluded because of incomplete clinical information and lack of TNM stage based on 7th AJCC standard (2010+). Eventually, 1694 patients were included, which were randomly divided into the development group (1188 patients) and the validation group (506 patients). The characteristics of these patients were summarized in Table 1. 
Table 1

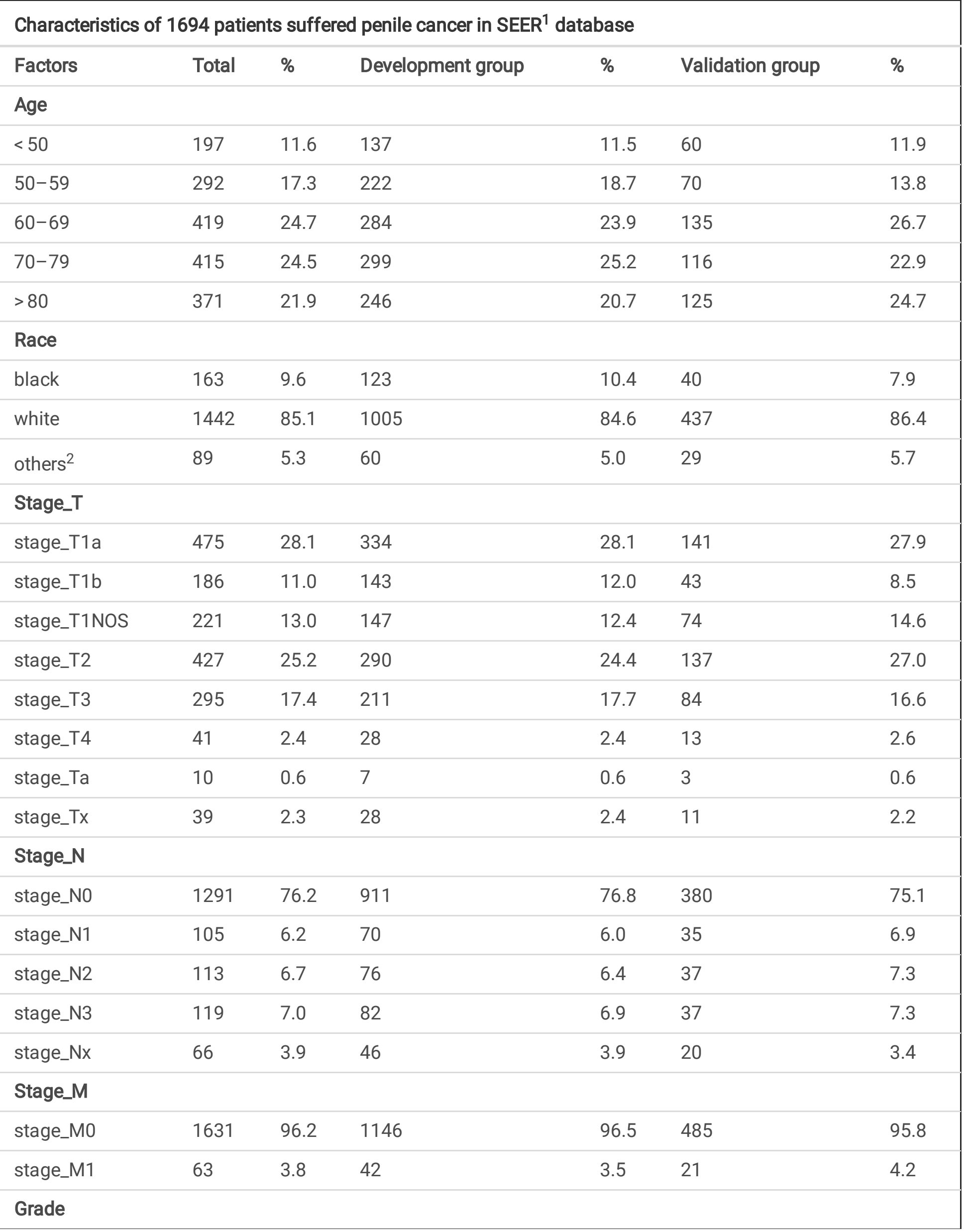




\begin{tabular}{|c|c|c|c|c|c|c|}
\hline \multicolumn{7}{|c|}{ Characteristics of 1694 patients suffered penile cancer in SEER ${ }^{1}$ database } \\
\hline grade_l & 468 & 27.6 & 309 & 26.0 & 159 & 31.4 \\
\hline grade_II & 822 & 48.6 & 592 & 49.8 & 230 & 45.5 \\
\hline grade_III & 390 & 23.0 & 273 & 23.0 & 117 & 23.1 \\
\hline grade_IV & 14 & 0.8 & 14 & 1.2 & 0 & 0 \\
\hline
\end{tabular}

In development group, the median follow-up was $32(95 \% \mathrm{Cl}, 30-36)$ months. However, the median of survival time was not applicable. (Fig. 1)

Univariate Cox proportional hazards regression demonstrated that age, stage $\mathrm{T}, \mathrm{N}$ and $\mathrm{M}$, and grade were significantly related to the survival of PC patients. Furthermore, results of multivariate cox regression showed that there were multiple prognostic factors were strongly independent, including age, stage T2, stage T3, stage T4, stage Tx, stage N, stage M1, and grade III. However, weak but insignificant correlation was found for stage T1b. Additionally, race was not independent both in univariate and multivariate Cox analyses. (Table 2) 
Table 2

univariate and multivariate Cox analyses based on penile cancer patients in development group univariate analyses multivariate analyses

$\begin{array}{lllllllll}\text { Factors } & \mathrm{HR}^{1} & \text { lower.95 } & \text { upper.95 } & \mathrm{P} \text { value } & \mathrm{HR}^{1} & \text { lower.95 } & \text { upper.95 } & \mathrm{P} \text { value }\end{array}$

\section{Age $(<50$}

reference)

\begin{tabular}{lllllllll}
$50-59$ & 1.289 & 0.8023 & 2.071 & 0.29406 & 1.2734 & 0.7893 & 2.054 & 0.321967 \\
\hline $60-69$ & 1.368 & 0.8711 & 2.148 & 0.17373 & 1.3936 & 0.8847 & 2.195 & 0.152280 \\
\hline $70-79$ & 1.813 & 1.1692 & 2.812 & $\begin{array}{l}0.00785 \\
\star \star\end{array}$ & 1.9309 & 1.2370 & 3.014 & $\begin{array}{l}0.003781 \\
\star \star\end{array}$ \\
$>80$ & 4.022 & 2.6237 & 6.165 & $\begin{array}{l}1.7 \mathrm{e}-10 \\
\star \star \star\end{array}$ & 4.3389 & 2.8015 & 6.720 & $\begin{array}{l}4.86 \mathrm{e}-11 \\
\star \star \star\end{array}$
\end{tabular}

\section{Race(black}

reference)

$\begin{array}{lllllllll}\text { white } & 0.8191 & 0.6015 & 1.116 & 0.206 & 0.8501 & 0.6175 & 1.170 & 0.319690 \\ \text { Others }^{2} & 0.9009 & 0.5376 & 1.510 & 0.692 & 0.9275 & 0.5453 & 1.578 & 0.781204\end{array}$

\section{Stage(stage_T1a}

reference)

stage_T1b

$1.908 \quad 1.3157$

2.768

0.00066

1.4984

$0.9613 \quad 2.335$

0.074140

$\begin{array}{lllllllll}\text { stage_T1NOS } & 1.311 & 0.8853 & 1.942 & 0.17645 & 1.3575 & 0.9109 & 2.023 & 0.133176 \\ \text { stage_T2 } & 2.124 & 1.5653 & 2.883 & \substack{1.32 \mathrm{e}-06 \\ * * *} & 1.5679 & 1.1286 & 2.178 & \substack{0.007339 \\ * *}\end{array}$

stage_T3

2.66

1.9410

3.655

$1.30 \mathrm{e}-0$

1.8276

1.2832

2.603

0.000833

stage_T4

$5.402 \quad 3.2049$

$9.104 \quad 2.41 \mathrm{e}-10$

4.7712

2.7571

8.257

$2.35 \mathrm{e}-08$

stage_Ta

1.240

0.3037

5.064

0.76435

2.0969

0.5036

8.731

0.308958

stage_Tx

4.461

$2.5452 \quad 7.820$

$1.76 \mathrm{e}-07$
$\star * *$

$2.3185 \quad 1.2088$

4.447

* 0.011385

\section{Stage(stage_NO reference)}

$\begin{array}{lccccccccc}\text { stage_N1 } & 2.017 & 1.410 & 2.885 & \begin{array}{l}0.000123 \\ \star \star \star\end{array} & 1.6712 & 1.1364 & 2.458 & \begin{array}{l}0.009055 \\ \star \star\end{array} \\ \text { stage_N2 } & 2.159 & 1.522 & 3.062 & \begin{array}{l}1.58 \mathrm{e}-05 \\ \star \star \star\end{array} & 1.6684 & 1.1417 & 2.438 & \begin{array}{l}0.008184 \\ \star \star\end{array} \\ \text { stage_N3 } & 2.868 & 2.079 & 3.957 & \begin{array}{l}1.38 \mathrm{e}-10 \\ \star \star \star\end{array} & 2.1150 & 1.4838 & 3.015 & \begin{array}{l}3.45 \mathrm{e}-05 \\ \star \star \star\end{array}\end{array}$




\begin{tabular}{|lcccccccc|}
\hline \multicolumn{7}{|c|}{ univariate and multivariate Cox analyses based on penile cancer patients in development group } \\
\hline stage_Nx & 2.242 & 1.422 & 3.536 & $\begin{array}{l}0.000512 \\
\star * \star\end{array}$ & 1.8153 & 1.0721 & 3.074 & 0.026486 \\
$*$
\end{tabular}

Prognostic nomogram involved all risk factors based on the data of development group was showed in Fig. 2. Corresponding scores were assigned to each factor, and the sum of scores reflected the 3-year and 5-year survival and mortality of patients. C-index of the nomogram model on the basis of development group was $0.732(95 \% \mathrm{Cl}$, $0.706-0.757)$. The result was reported to be $0.743(95 \% \mathrm{Cl}, 0.703-0.782)$ in the verification group, which was significantly superior to that in development group.

The AUC of 3- and 5-year survival were 0.739 and 0.727 (Fig. 3), which indicated the reliability of the nomogram. The 3- and 5-year calibration curves of development group also showed satisfying consistency between the observed and predicted outcomes (Fig. 4).

More intuitional differences were showed in Kaplan-Meier analyses (Fig. 5, A-G). Function of "coxph" package was used to build the proportional-risk model. After comparing with the median risk, patients were divided into high-risk and low-risk groups, from which the high-risk group gained lower survival in 3 years (44.5\%, 95\% Cl, 39.9\%-49.6\%) and 5 years $(35.9 \%, 95 \% \mathrm{Cl}, 30.6 \%-42.3 \%)(\mathrm{P}<0.0001)$ (Fig. 5, A). Further, patients with age of $>80$ and $70-79$ showed significantly lower survival compared with the younger $(P<0.0001)$ (Fig. $5, B)$. Significant differences of Kaplan-Meier curves were observed in stage T, N and M, and grade as well (Fig. 5, C-F). However, no significant difference could be found among patients with different races, though the white patients had a slight but insignificant advantage in long-term survival $(P=0.43)$ (Fig. $5, G)$.

C-index, AUC and calibration curves were respectively used to evaluate the accuracy of the nomogram. On the basis of the verification group, statistical results showed that the C-index was $0.743(95 \% \mathrm{Cl}, 0.703-0.782)$, which was higher than 0.7 and better than the development group. Meanwhile, the AUC of 3-and 5-year survival in validation group were 0.725 and 0.729 , respectively (Fig. 6). The observed-predicted calibration curves of 3- and 5-year also showed similar results (Fig. 7). All of these results proved the worth of the nomogram.

\section{Discussion}


Although there were some differences in hygienic, social and religious practice [14], PC, mostly squamous cell carcinoma [15], was still a rare disease over the past decades [16-18]. In most developed areas, the incidence of PC was even decreasing gradually $[19,20]$. However, due to uncommon clinical cases and lack of reliably prognostic tools in assessment, clinicians seemed to have limited method in understanding and predicting the prognosis of PC.

As a tool for predicting patients' prognosis, nomogram was widely used in oncology, such as bladder cancer, prostatic cancer and breast cancer [21-23]. Its capability was to provide a more individualized prognostic assessment for patients by combining various prognostic risk factors which had been widely recognized [24]. Our prognostic nomogram was based on the database of SEER, which had collected the detailed information of approximately 34.6 percent of the U.S. population [25].

In our study, elderly patients, especially those older than 80 , would have a significantly lower 3-year (34.6\%, 95\% Cl, $27.9 \%-42.7 \%)$ and 5-year $(23.5 \%, 95 \% \mathrm{Cl}, 16.4 \%-33.7 \%)$ survival $(\mathrm{P}<0.0001)$. Simultaneously, these patients were also weighted more points than others. Kaplan-Meier curve of age showed that only slight difference in OS could be found among all groups under 70 (643/1188 of development group). These evidences proved that elder age might be an independent risk factor for the prognosis of PC patients, which was consistent with most studies [18].

According to the study by Sharma et al., black males who were suffered from PC would have a worse OS [26]. In addition, Slopnick et al. declared that African-American PC patients probably had a higher risk of death compared with the white [27]. However, in our study, both in the result of cox regression and Kaplan-Meier curve, no significant difference was found in the comparison among white, black and other races. This might be helpful to explore the real answer of higher mortality rate in some areas, instead of the superiority of race.

Furthermore, results of cox regression analyses also suggested the importance of cancer stage in the prognostic evaluation of patients. But it seemed to be not significant among some subgroups, including stage T1a, stage T1b and stage T1NOS. Similar to most studies, lymph node involvement and distant metastasis remained independent risk factors for patients' prognosis [28].

The recent guideline on PC from European Association of Urology strongly affirmed the importance of strict grade in pathological assessment [29]. Aita et al. claimed that high histopathological grade was responsible for a poor prognosis based on a study with an average follow-up more than 3 years involving 163 PC patients [30]. Other studies also emphasized the importance of pathologic grade [31,32]. But, in our study, it seemed that the histopathological grade played a different role in the assessment of patients' prognosis except for the grade III. However, for Grade IV, only 14 (0.8\%) patients were included, which might cause a statistical bias.

Above all, some limitations in our study must be taken into consideration. Firstly, the SEER database was a retrospective resource library including patients over a long period span, which might lead to an inevitable bias. Secondly, data about habit, custom (especially for sexual activity), human papilloma virus infection, average income, religion, smoking, education, Charlson comorbidity index and other information could not be available in the SEER database, which could also affect the quality of our results. Finally, no additional data of PC patients from other sources or institutions could be used for external verification, which might cause a selected bias.

\section{Conclusion}


No prognostic prediction model was widely accepted for PC patients so far. The results demonstrated that our nomogram model would be feasible and reliable, and we thought it could be helpful for clinicians to be faster and more accurately to evaluating the prognosis of PC patients. However, because of the limitations in our study, more prospective studies are needed to verify the accuracy of the nomogram.

\section{Declarations}

\section{ACKNOWLEDGEMENTS}

We would like to thank the SEER program.

\section{AUTHORS' CONTRIBUTIONS}

Yong-Bo Chen, Liang Gao and Ping-Hong You designed the study. Yong-Bo Chen and Liang-You Tang selected and analysed the data. Yong-Bo Chen, Jiang Guo and Yu-Chang Tian involved in statistical analysis. Yong-Bo Chen, Liang Gao, Liang-You Tang and Ping-Hong You drafted and revised the manuscript. All authors have reviewed and approved the final manuscript.

\section{FUNDING}

Not applicable.

\section{AVAILABILITY OF DATA AND MATERIALS}

The dataset supporting the conclusions of this study is available in the SEER database

\section{ETHICS APPROVAL}

Not applicable.

\section{CONSENT FOR PUBLICATION}

Not applicable.

\section{COMPETING OF INTERESTS}

The authors declare that they have no conflict of interest.

\section{References}

1. Schoffer O, Neumann A, Stabenow R, Schülein S, Böhm WD, Gonsior A, Horn LC, Kriegel C, Stolzenburg JU, Wirth M, Klug SJ. Penile cancer - Incidence, mortality, and survival in Saxony, Germany. Urol Oncol. 2019;37:295.

2. Daubisse-Marliac L, Colonna M, Trétarre B, Defossez G, Molinié F, Jéhannin-Ligier $K$, Marrer E; FRANCIM network, Grosclaude P. Long-term trends in incidence and survival of penile cancer in France. Cancer Epidemiol. 2017;50:125-131.

3. Sharma P, Zargar-Shoshtari K, Pettaway CA, Schabath MB, Giuliano AR, Spiess PE. Disparities in Penile Cancer. Cancer Control. 2016;23:409-414. 
4. Serrano B, Brotons M, Bosch FX, Bruni L. Epidemiology and burden of HPV-related disease. Best Pract Res Clin Obstet Gynaecol. 2018;47:14-26.

5. Backes DM, Kurman RJ, Pimenta JM, Smith JS. Systematic review of human papillomavirus prevalence in invasive penile cancer. Cancer Causes Control. 2009;20:449.

6. Hartwig S, Syrjänen S, Dominiak-Felden G, Brotons M, Castellsagué X. Estimation of the epidemiological burden of human papillomavirus-related cancers and non-malignant diseases in men in Europe: a review. BMC Cancer. 2012;12:30.

7. Stern RS. The risk of squamous cell and basal cell cancer associated with psoralen and ultraviolet $A$ therapy: a 30-year prospective study. J Am Acad Dermatol. 2012;66:553.

8. Dillner J, von Krogh G, Horenblas S, Meijer CJ. Etiology of squamous cell carcinoma of the penis. Scand J Urol Nephrol Suppl. 2000;205:189-93.

9. Maden C, Sherman KJ, Beckmann AM, Hislop TG, Teh CZ, Ashley RL, Daling JR. History of circumcision, medical conditions, and sexual activity and risk of penile cancer. J Natl Cancer Inst. 1993;85:19-24.

10. Tsen HF, Morgenstern H, Mack T, Peters RK. Risk factors for penile cancer: results of a population-based casecontrol study in Los Angeles County (United States). Cancer Causes Control. 2001;12:267-77.

11. Kim JW, Kim YS, Ko WJ, Choi YD, Hong SJ, Chung BH, Lee KS. Prognostic Factors of Penile Cancer and the Efficacy of Adjuvant Treatment after Penectomy: Results from a Multi-institution Study. J Korean Med Sci. 2018;33:e233.

12. Amin MB, Greene FL, Edge SB, Compton CC, Gershenwald JE, Brookland RK, Meyer

13. L, Gress DM, Byrd DR, Winchester DP. The Eighth Edition AJCC Cancer Staging Manual: continuing to build a bridge from a population-based to a more "personalized" approach to cancer staging. CA Cancer J Clin. 2017;67:93-9.

13. Brierley JD, Gospodarowicz MK, Wittekind C, editors. The TNM classification of malignant tumours. Oxford: Wiley Blackwell.

14. Misra S, Chaturvedi A, Misra NC. Penile carcinoma: A challenge for the developing world. Lancet Oncol. 2004;5:240-7.

15. Hakenberg OW, Dräger DL, Erbersdobler A, Naumann CM, Jünemann KP, Protzel C. The Diagnosis and Treatment of Penile Cancer. Dtsch Arztebl Int. 2018;115:646-652.

16. Chaux A, Netto GJ, Rodríguez IM, Barreto JE, Oertell J, Ocampos S, Boggino H, Codas R, Xavier Bosch F, de Sanjose S, Muñoz N, Hildesheim A, Cubilla AL. Epidemiologic profile, sexual history, pathologic features, and human papillomavirus status of 103 patients with penile carcinoma. World J Urol. 2013;31:861-7.

17. Cancer Incidence in Five Continents Vol. VIII. IARC Scientific Publication No. 155. Vol. Vol III. 2002, The International Agency for Research on Cancer, 150 cours Albert Thomas, 69372 Lyon CEDEX 08, France.

18. Arya M, Li R, Pegler K, Sangar V, Kelly JD, Minhas S, Muneer A, Coleman MP. Long-term trends in incidence, survival and mortality of primary penile cancer in England. Cancer Causes Control. 2013;24:2169-76.

19. Baldur-Felskov B, Hannibal CG, Munk C, Kjaer SK. Increased incidence of penile cancer and high-grade penile intraepithelial neoplasia in Denmark 1978-2008: a nationwide population-based study. Cancer Causes Control. 2012;23:273-80.

20. Barnholtz-Sloan JS, Maldonado JL, Pow-sang J, Giuliano AR. Incidence trends in primary malignant penile cancer. Urol Oncol. 2007;25:361-7. 
21. Wu S, Zheng J, Li Y, Yu H, Shi S, Xie W, Liu H, Su Y, Huang J, Lin T. A. Radiomics Nomogram for the Preoperative Prediction of Lymph Node Metastasis in Bladder Cancer. Clin Cancer Res. 2017;23:6904-6911.

22. Brockman JA, Alanee S, Vickers AJ, Scardino PT, Wood DP, Kibel AS, Lin DW, Bianco FJ Jr, Rabah DM, Klein EA, Ciezki JP, Gao T, Kattan MW, Stephenson AJ. Nomogram Predicting Prostate Cancer-specific Mortality for Men with Biochemical Recurrence After Radical Prostatectomy. Eur Urol. 2015;67:1160-1167.

23. Chen S, Liu Y, Yang J, Liu Q, You H, Dong Y, Lyu J. Development and Validation of a Nomogram for Predicting Survival in Male Patients With Breast Cancer. Front Oncol. 2019;9:361.

24. Balachandran VP, Gonen M, Smith JJ, DeMatteo RP. Nomograms in oncology: more than meets the eye. Lancet Oncol. 2015;16:e173-80.

25. National Cancer Institute. Surveillance, Epidemiology and End Results Program. Available at: http://seer.cancer.gov/.

26. Sharma P, Ashouri K, Zargar-Shoshtari K, Luchey AM, Spiess PE. Racial and economic disparities in the treatment of penile squamous cell carcinoma: results from the national cancer database. Urologic Oncol: Semin Ori Invest. 2016;34:122-129.

27. Slopnick EA, Kim SP, Kiechle JE, Gonzalez CM, Zhu H, Abouassaly R. Racial disparities differ for African Americans and hispanics in the diagnosis and treatment of penile cancer. Urology. 2016;96:22-28.

28. Zhu Y, Ye DW. Lymph node metastases and prognosis in penile cancer. Chin J Cancer Res. 2012;24:90-6.

29. Hakenberg OW, Compérat EM, Minhas S, Necchi A, Protzel C, Watkin N. EAU guidelines on penile cancer: 2014 update. Eur Urol. 2015;67:142-150.

30. Aita GA, Zequi SC, Costa WH, Guimarães GC, Soares FA, Giuliangelis TS. Tumor histologic grade is the most important prognostic factor in patients with penile cancer and clinically negative lymph nodes not submitted to regional lymphadenectomy. Int Braz J Urol. 2016;42:1136-1143.

31. Nam JK, Lee DH, Park SW, Kam SC, Lee KS, Kim TH, Kim TS, Oh CK, Park HJ, Kim TN. Clinicopathologic Characteristics and Treatment Outcomes of Penile Cancer. World J Mens Health. 2017;35:28-33.

32. Cubilla AL. The role of pathologic prognostic factors in squamous cell carcinoma of the penis. World J Urol. 2009;27:169-77.

\section{Figures}


development group + all patients

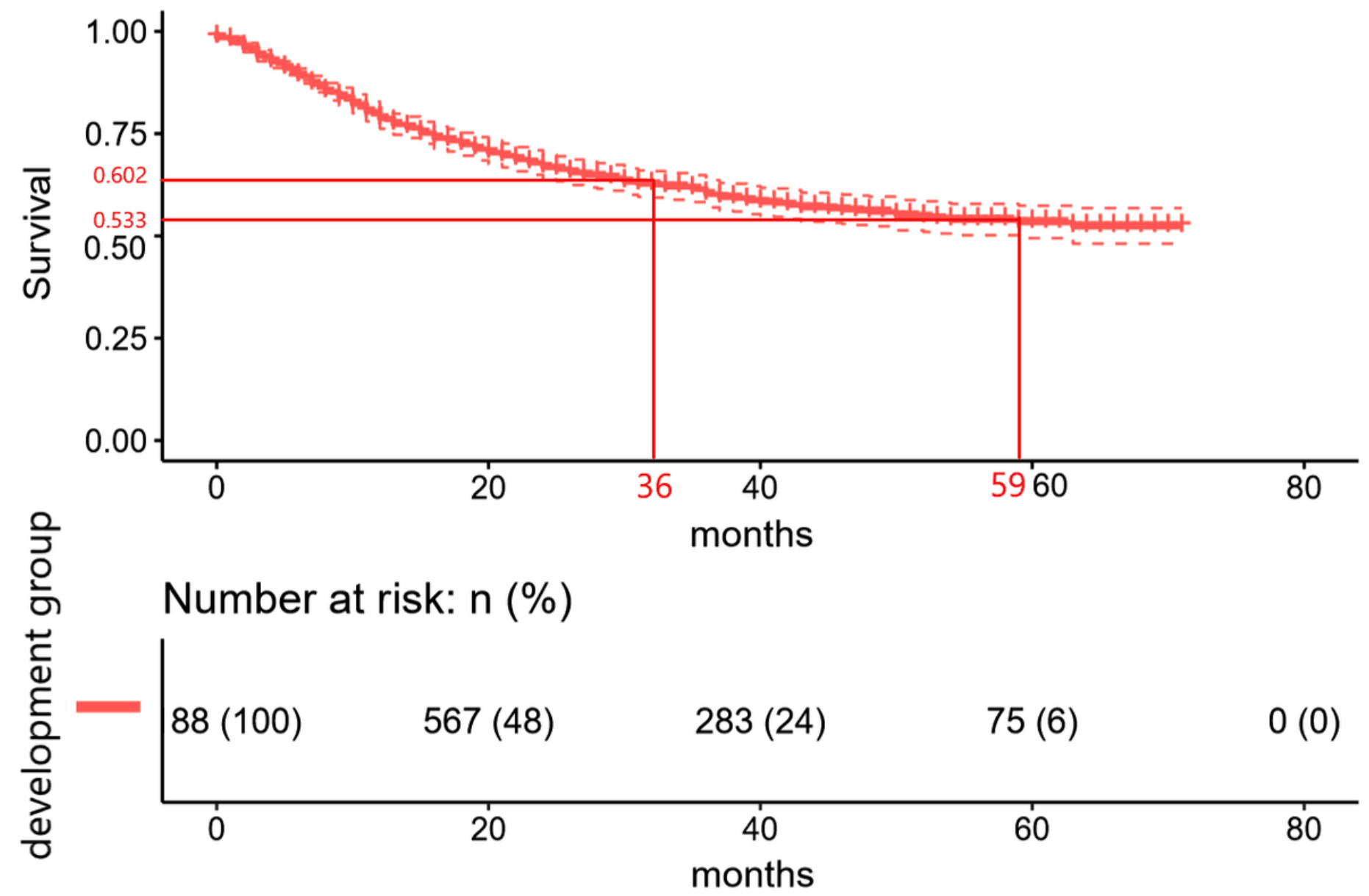

Figure 1

Figure 1 
Points

$\begin{array}{lllllllllll}0 & 10 & 20 & 30 & 40 & 50 & 60 & 70 & 80 & 90 & 100\end{array}$

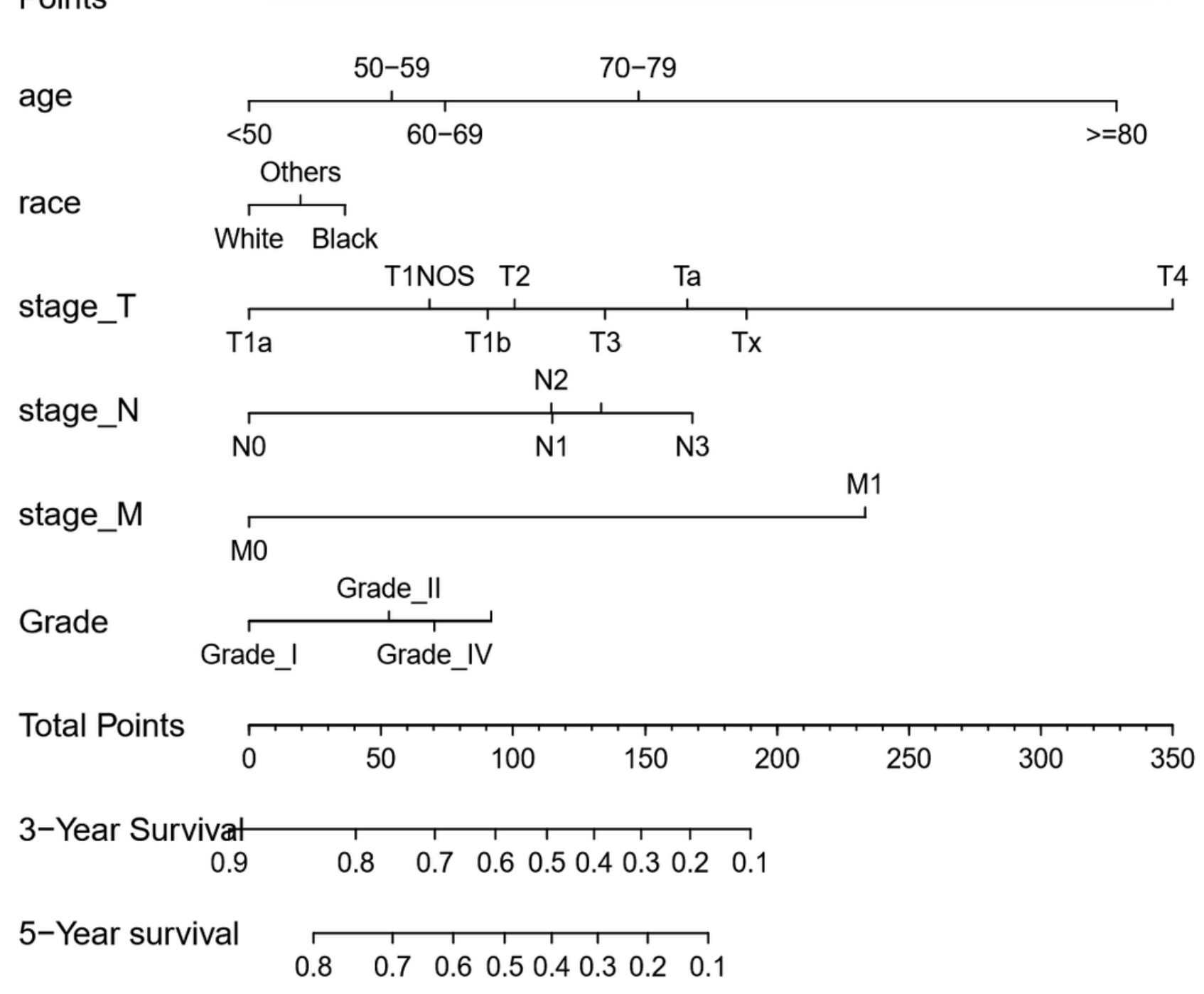

Figure 2

Figure 2 


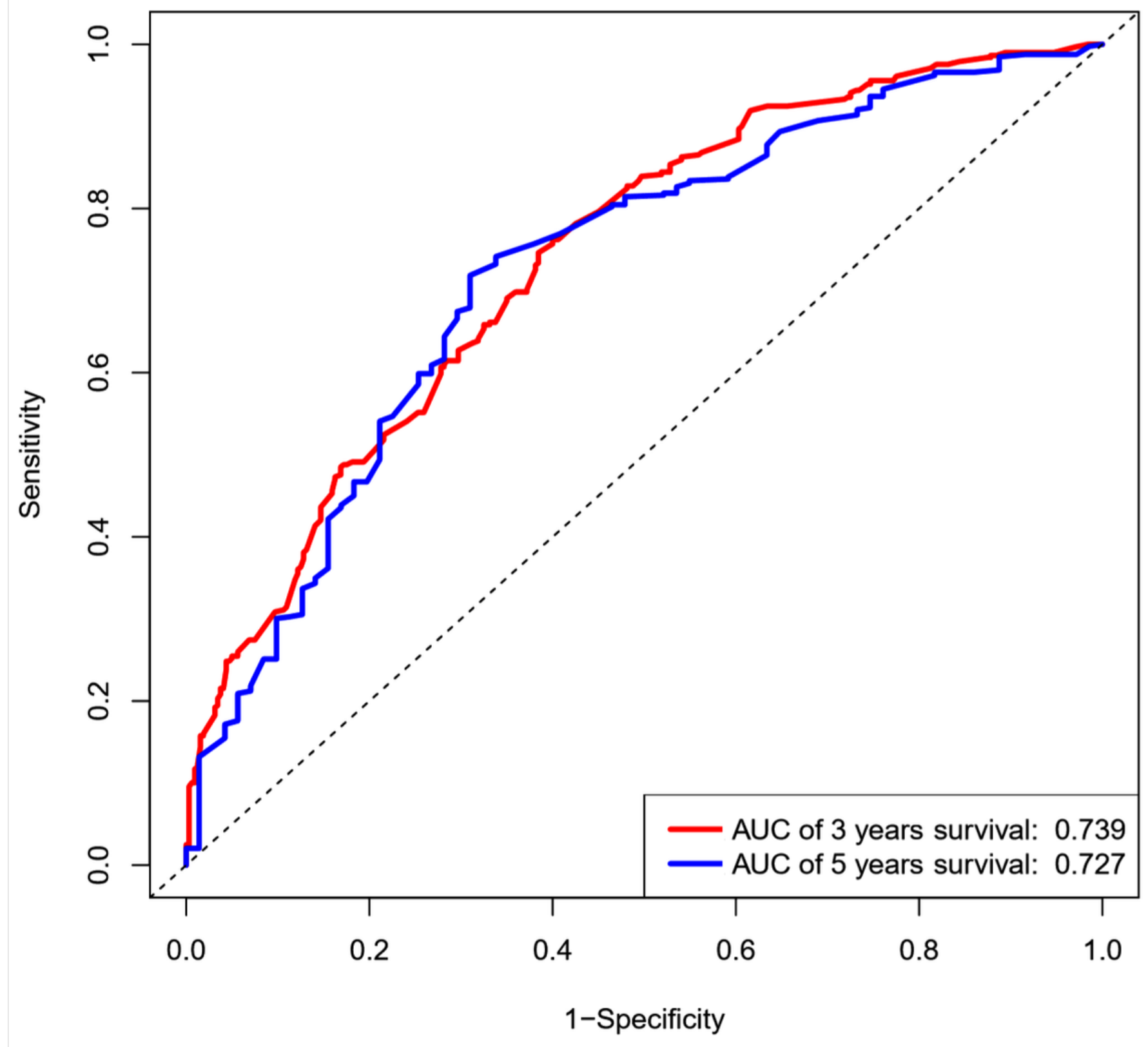

Figure 3

Figure 3 


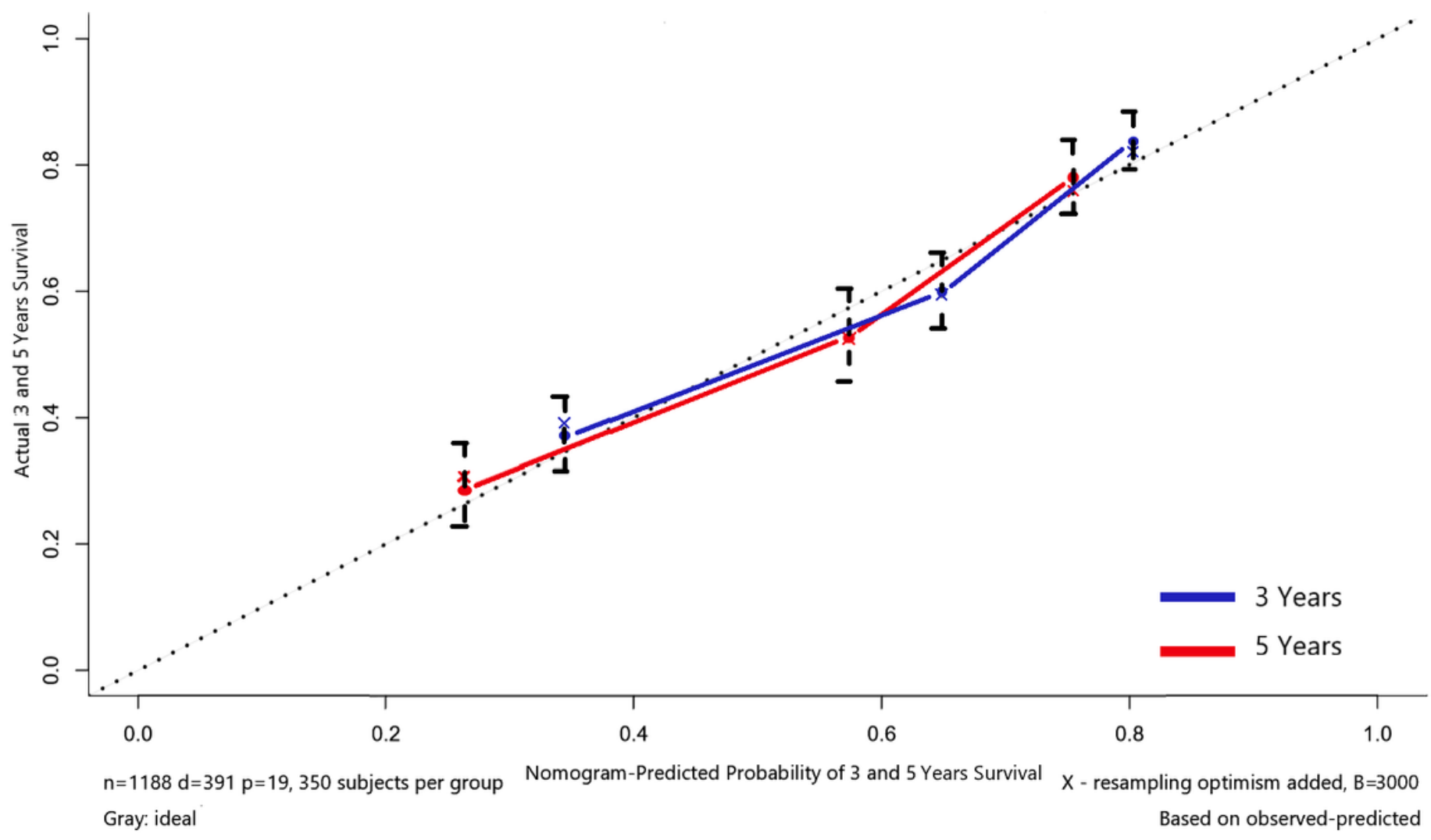

Figure 4

Figure 4 

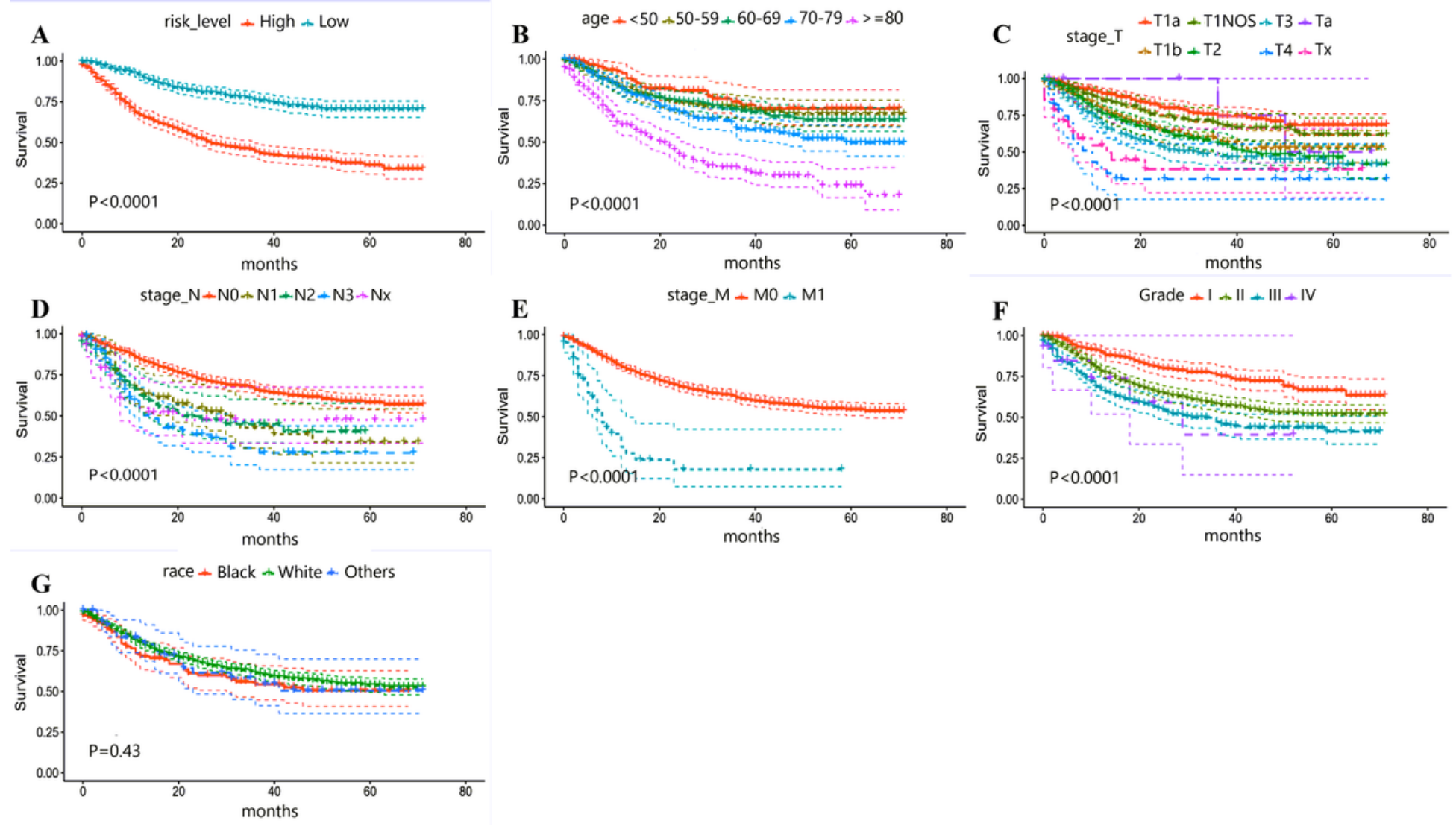

\section{Figure 5}

Figure 5 


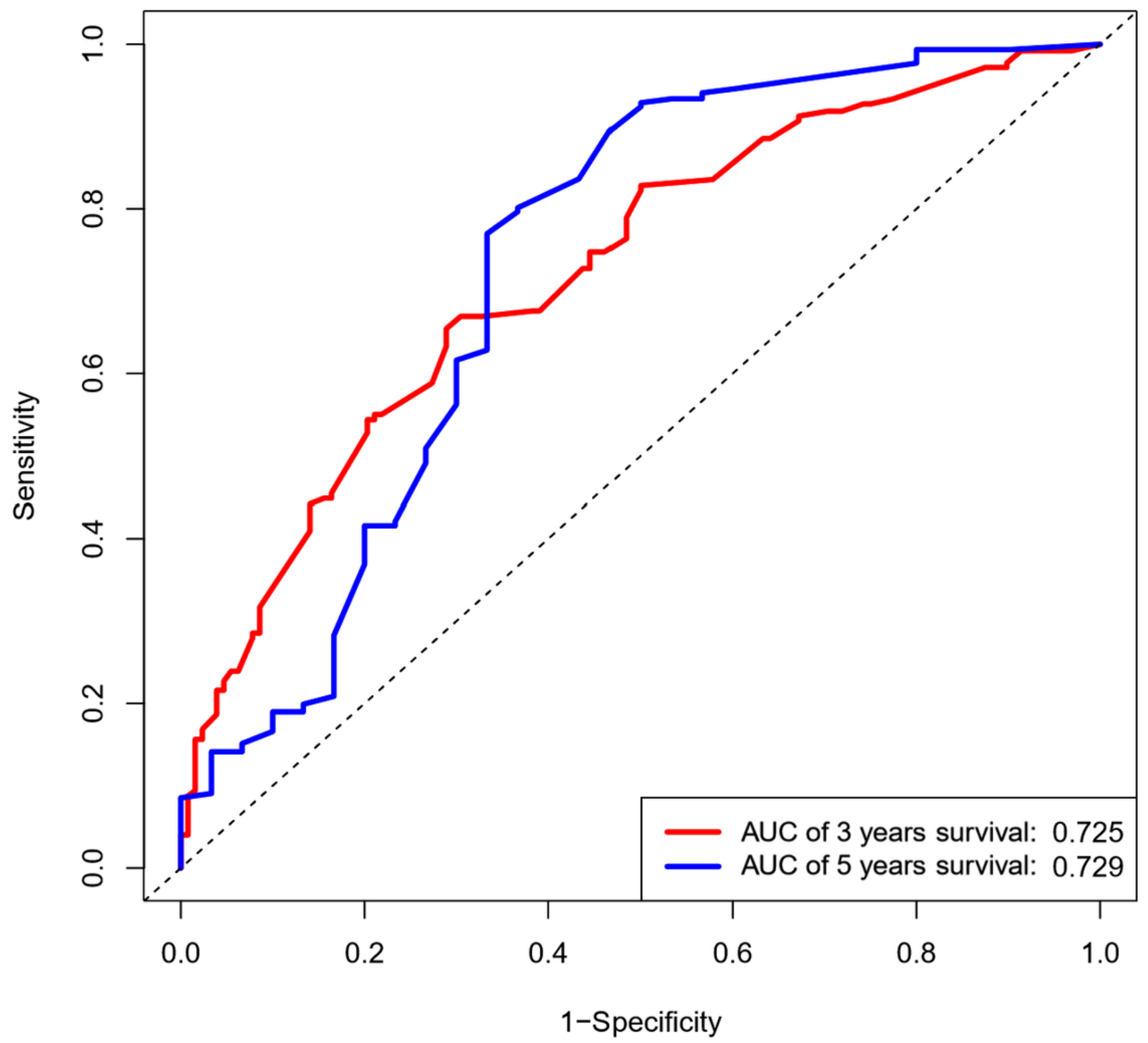

Figure 6

Figure 6 


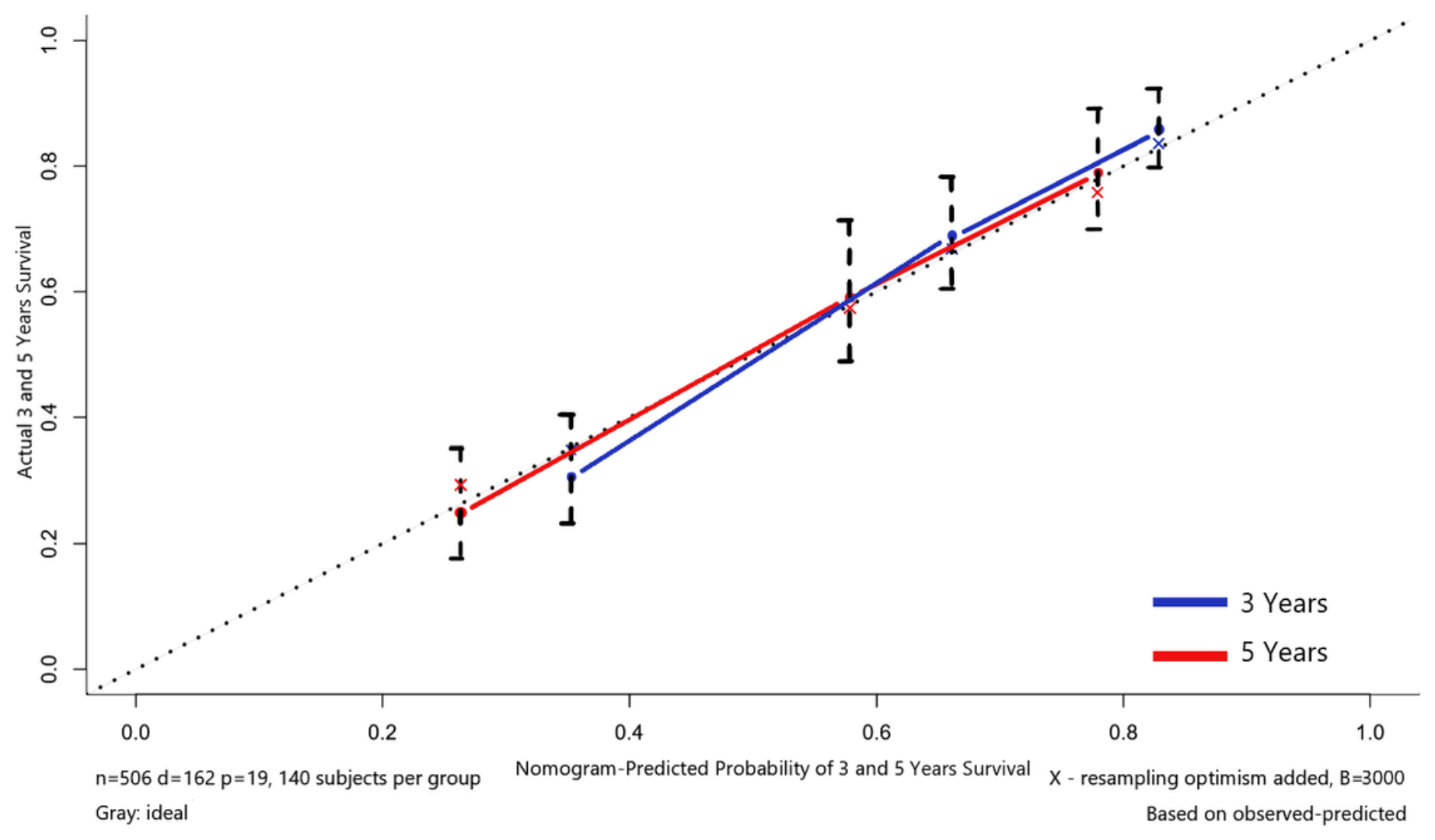

Figure 7

Figure 7 